\title{
Parasagittal hemangioma associates with unilateral cheiro-oral-pedal syndrome
}

\author{
Hung Sheng Lin, Chun Chung Lui, Wei Hsi Chen, Jia Shou Liu \\ Departments of Neurology and Neuroradiology, Chang Gung Memorial Hospital, Niao Sung Hsiang, Taiwan
}

Cortical lesion might elicit restricted acral sensory deficit but a disparity of topographies in cheiro-oral-pedal syndrome is very rare. We report the first case of cheiro-oral-pedal syndrome due to a contralateral parasagittal hemangioma involving the supplement sensory area in parietal lobe. This unusual link between neuroanatomy and neurological feature is discussed.

Keywords: Cheiro-oral-pedal syndrome, parietal lobe, hemangioma, sensory

\section{Introduction}

Cheiro-oral-pedal syndrome (COPS) is a sensory disorder, firstly reported in 1992 by Yasuda et al, ${ }^{[1]}$ restricted to the homolateral perioral region, fingers/hand and toes/foot. Till now, only a limited number of COPS patients have formally been reported in literature. ${ }^{[2]}$ The COPS usually arises from an involvement of the ascending spinotrigeminothalamic tract at thalamus and less, pons or thalamocortical projection. ${ }^{[2]}$ Two questions are still whirling in this sensory disorder. First, the involved body parts separate distantly. Second, the paroxysmal relapse of sensorum in COPS is substantially unknown. We encountered a woman with an unusual cortical lesion presenting with COPS. The mechanism is discussed.

\section{Case history}

A 64-year-old hypertensive woman received antihypertensive treatment regularly more than 20 years. However, episodic concurrence of palpitation, anterior chest tightness, neck soreness and an elevation of systolic blood pressure over 200 $\mathrm{mmHg}$ in spontaneity occurred 2 years ago. Initially, the frequency was once in every 2 to 3 months and the duration was less than 15 minutes. One week before admission, the fre- quency of these events increased to daily basis. Meanwhile, a new onset of numbness confined to her mouth angle, hand and foot also developed. Her numbness was accompanied with an elevation of systole over $160 \mathrm{mmHg}$ every time. It lasted for 5 minutes, subsided, and then recurred over 4 to 5 times daily. Five days later, her numbness became persistent without recovery. She denied having familial disease, diabetes mellitus, migraine, recent head injury, toxic substance exposure nor consumption of herb, illicit drug, beverage or cigarette.

On presentation, her vital signs were stable. She was conscious and oriented. Her speech and cognition were normal. Pupils were isocoric and reactive, and their sizes were $3.0 \mathrm{~mm} /$ $3.0 \mathrm{~mm}$. Visual acuity was $20 / 20$ and visual field was not limited. Neuro-ophthalmology, cranial nerves, motor function, co-

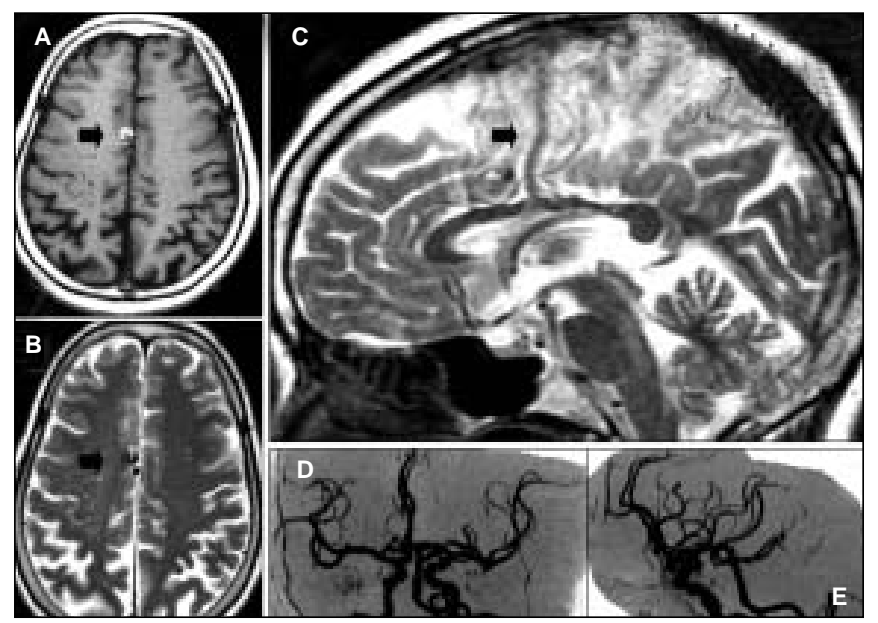

Figure 1: The magnetic resonance neuroimaging of this patient showed a heterogenous, high T1-weighted intensity lesion ( $A$, arrow) and T2-weighted intensity lesion at the parasagittal region of parietal lobe ( $B$, arrow) involving the medial precentral gyrus and cingulate gyrus, especially the right side. Mild perifocal edema was present. Subacute hemorrhage was compatible. There was an engorgement of a cortical drainage vein (arrow) at the medial aspect of hemisphere (C). Cavernous hemangioma was favored. Magnetic resonance angiogram revealed mild atherosclerosis in the proximal intracranial arteries and no aneurysm or other anomaly was seen $(D, E)$ 
ordination and equilibrium were normal. Corneal reflex was intact. Pinprick pain and cotton fine touch sensation decreased mildly $(10 \%)$ at the left hemibody, but densely $(80 \%)$ at the perioral region, fingers, hand, and foot. Vibratory sense and joint position sensation were intact. Cortical sensation decreased $20 \%$ on left side. COPS was interpreted. Head magnetic resonance image revealed a heterogenous, high $\mathrm{T} 1$ and T2-weighted intensity lesion at the parasagittal region of parietal lobe involving the medial precentral gyrus and cingulate gyrus, especially the right side (Figure 1). Supplementary sensory area was involved. Mild perifocal edema was present. Subacute hemorrhage was considered. An inhomogenous uptake of contrast within the lesion was seen. An engorgement of a cortical drainage vein at the medial aspect of hemisphere was also noted. Cavernous hemangioma was favored. Magnetic resonance angiogram revealed mild atherosclerosis at proximal intracranial arteries. Electroencephalogram did not show any paroxysmal discharge during sensory attack. Somatosensory evoked potential did not reveal any abnormal change of amplitude or latency at median and peroneal nerve stimulation. Biochemistry, hematology, serology, urinalysis, cardiac function and stroke risk factor survey ${ }^{[3]}$ were normal. During hospitalization, her COPS exacerbated when systole increased to over $180 \mathrm{mmHg}$. The severity of sensorum decreased following with a reduction of arterial blood pressure. She and her family refused any further investigation and treatment. Her numbness progressively subsided within one month without topographic sequence. On a follow up of 6 months, she was uneventful and her blood pressure was controlled well.

\section{Discussion}

To our knowledge, this patient is the first report of COPS associated with cortical lesion. Till now, there are a total of 31 COPS patients reported in literature [Table 1]. ${ }^{[1-2,4-9]}$ Including our patient herein, they are 18 men and 14 women. The age ranged from 37 to 81 . Over $53 \%$ patients were older than 65 years.

Thalamus is involved in 23 out of 32 patients, following by pons in 7 and thalamocortical projection in another 1 patient, respectively (Table 1). Our patient is the only one to have cortical lesion. A close proximity of the ascending tracts from the perioral region, fingers/hand and toes/foot could explain the characteristic picture of COPS in subcortical but not cortical level. A low prevalence of cortical involvement in COPS may reflect a more distant disparity of the representation areas of perioral structure, fingers/hand and toes/foot in sensory cortex than the cheiro-oral syndrome.

Currently, at least five hypotheses have been proposed for the occurrence of cheiro-oral syndrome but they do not fully explain this peculiar sensory disorder: ${ }^{[10]}$ (1) epileptogenesis was suggested in prior but an absence of paroxysmal discharge and change of pituitary hormones in ictus discarded this possibility; (2) migraine is less likely as the time onset, clinical

\begin{tabular}{|c|c|c|c|c|c|c|}
\hline References $\mathrm{C}$ & Case & Age & Sex & Location & Etiology & deficits \\
\hline Present case & 1 & 64 & $\mathrm{~F}$ & Cortex & Hematoma & \\
\hline \multirow[t]{8}{*}{2} & 2 & 62 & $\mathrm{M}$ & Thalamus & Infarct & \\
\hline & 3 & 56 & $\mathrm{M}$ & Thalamus & Infarct & \\
\hline & 4 & 60 & $\mathrm{~F}$ & Thalamus & Infarct & \\
\hline & 5 & 57 & $\mathrm{M}$ & Thalamus & Infarct & \\
\hline & 6 & 65 & $\mathrm{~F}$ & Thalamus & Infarct & \\
\hline & 7 & 72 & M & Thalamus & Infarct & \\
\hline & 8 & 66 & M & Thalamus & Infarct & \\
\hline & 9 & 69 & $\mathrm{~F}$ & Thalamus & Infarct & \\
\hline \multirow[t]{6}{*}{4} & 10 & 69 & M & Thalamus & Infarct & \\
\hline & 11 & 71 & M & Thalamus & Infarct & \\
\hline & 12 & 72 & M & Thalamus & Infarct & \\
\hline & 13 & 69 & M & Thalamus & Infarct & \\
\hline & 14 & 69 & M & Thalamus & Infarct & \\
\hline & 15 & 78 & M & Thalamus & Infarct & \\
\hline 5 & 16 & 79 & M & PT & Infarct & \\
\hline \multirow[t]{3}{*}{6} & 17 & 53 & $M$ & $\begin{array}{l}\text { PT } \\
\text { hemiparesis }\end{array}$ & Infarct & Homolateral \\
\hline & 18 & 63 & $\mathrm{~F}$ & $\begin{array}{l}\text { VPM, } \\
\text { VPL }\end{array}$ & Infarct & $\begin{array}{l}\text { Homolateral } \\
\text { hemiparesis }\end{array}$ \\
\hline & 19 & 73 & $\mathrm{~F}$ & VPM, VPL & Infarct & \\
\hline 7 & 20 & 47 & $F$ & $\begin{array}{l}\text { TC } \\
\text { projection }\end{array}$ & Hematoma & $\begin{array}{l}\text { Homolateral } \\
\text { hemiparesis }\end{array}$ \\
\hline \multirow[t]{8}{*}{8} & 21 & 50 & M & Thalamus & Infarct & \\
\hline & 22 & 57 & $\mathrm{~F}$ & Thalamus & Infarct & \\
\hline & 23 & 62 & $\mathrm{~F}$ & Thalamus & Infarct & \\
\hline & 24 & 55 & $M$ & $\begin{array}{l}\text { Thalamus } \\
\text { choreoathetos }\end{array}$ & $\begin{array}{l}\text { Infarct } \\
\text { sis }\end{array}$ & Homolateral \\
\hline & 25 & 50 & $\mathrm{~F}$ & $\begin{array}{l}\text { Thalamus } \\
\text { hemiparesis }\end{array}$ & ${ }_{S}^{\text {Infarct }}$ & Homolateral \\
\hline & 26 & 80 & M & PT & Infarct & \\
\hline & 27 & 56 & M & $\begin{array}{l}\text { PT } \\
\text { hemiparesis }\end{array}$ & Infarct & Homolateral \\
\hline & 28 & 37 & $\mathrm{~F}$ & PT & Infarct & Ataxia \\
\hline \multirow[t]{2}{*}{9} & 29 & 72 & $\mathrm{~F}$ & VPM, VPL & Infarct & \\
\hline & 30 & 65 & $\mathrm{~F}$ & VPM, VPL & Infarct & \\
\hline \multirow[t]{2}{*}{1} & 31 & 81 & F & PT & $\begin{array}{l}\text { Hematoma } \\
\text { hemiparesis }\end{array}$ & Homolateral \\
\hline & 32 & 76 & M & PT & Infarct & \\
\hline
\end{tabular}

Location: PT, pontine tegmentum; TC projection, thalamocortical projection; VPL, ventral posteriolateral nucleus; VPM, ventral posteriomedial nucleus.

picture, age of onset, and an absence of aura or headache during sensory attack do not support this consideration; (3) an unusual dual vascular supply has been proposed but cannot be confirmed; (4) a preconditioned neuronal vulnerability is only illustrated in cortical motor neuron but not cortical sensory neuron; (5) a combination of the above proposals has been suggested but there is no evidence to support.

In our patient, a link was seen between an overshooting of arterial blood pressure and occurrence of sensorum. A rapidity of relapsing sensory deficit in cases of cheiro-oral syndrome ${ }^{[11]}$ has been described in association with an exacerbation of previous hypertension that is known to render vasoconstriction such as in posterior ischemic leukoencephalopathy syndrome. ${ }^{[12]}$ Therefore, with previous reports and our experience, we believe that a complexity of consequences predicts the unusual occurrence of COPS. We propose that a pre-existing brain damage (old age, high frequency of cardiovascular risk factors) and a preconditioned neuronal vulnerability, if under vascular compromise (low perfusion, stroke, brain tumor and others), might provoke this peculiar sensory deficit in cortical level. The paroxysm is probably a result of vascular compromise. 


\section{Lin et al: Cheiro-oral-pedal syndrome}

COPS is an incomplete pure sensory syndrome, which mostly results from lacunar stroke, stabilizes rapidly after onset and recovers favorably. ${ }^{[13]}$ From our patient, a concomitant nonsensory neurological deficit or a fluctuation of sensory syndrome should caution for a nonlacunar course as in our patient.

\section{References}

1. Yasuda Y, Morita T, Okada T, Seko S, Akiguchi I, Kimura J. Cheiro-oral-pedal syndrome. Eur Neurol 1992;32:106-8.

2. Chen WH, Lin HS, Su CS, Chen SS, Liu JS. Cheiro-oral-pedal syndrome [Chinese]. J Kaohsiung County Med Assoc 2005;16:15-8.

3. Chen WH, Lan MY, Chang YY, Chen SS, Liu JS. The prevalence of protein C, protein $\mathrm{S}$, and antithrombin III deficiency in non-APS/SLE Chinese adults with noncardiac cerebral ischemia. Clin Appl Thromb Hemost. 2003;9:155-62.

4. Arboix A, Tomas J. Clinical study of 17 patients with cheiro-oral-pedal syndrome. Med Clin (Bare) 2002;118:180-2.

5. Terai S, Hori T, Tamaki K, Saishoji A. Early detection of small pontine infarction presenting cheiro-oral-pedal syndrome by diffusion-weighted magnetic reso- nance imaging. Eur Neurol 2000;44:119-20.

6. Yasuda Y, Watanabe T, Tanaka H, Akiguchi I, Kimura J, Kameyama M. Unusual sensory disturbance in the thoracic region after stroke: relationship to cheiro-oral and cheiro-oral-pedal syndrome. J Neurol Sci 1997;153:68-75.

7. Yasuda Y, Watanabe T, Akiguchi I, Kimura J, Kameyama M. Cheiro-oral-pedal syndrome in the lesion of thalamocortical projections. Clin Neurol Neurosurg 1994;96:185-7.

8. Kim JS: Restricted acral sensory syndrome following minor stroke. Further observation with special reference to differential severity of symptoms among individual digits. Stroke 1994;25:2497-502.

9. Yasuda Y, Matsuda I, Akiguchi I, Kameyama M. Cheiro-oral-pedal syndrome in thalamic infarction. Clin Neurol Neurosurg 1993;95:311-4.

10. Chen WH, Lan MY, Chang YY, Liu JS, Chou MS, Chen SS. Bilateral cheirooral syndrome. Clin Neurol Neurosurg 1997;99:239-43.

11. Chen WH, Tseng YL, Lui CC, Liu JS. Episodic pain syndrome restricted to cheiro-oral region associated with pontine lesion. Brain injury (in press).

12. Chen TH, Huang CC, Chang YY, Chen YF, Chen WH, Lai SL. Vasoconstriction as the etiology of hypercalcemia-induced seizures. Epilepsia 2004;45:551-4.

13. Arboix A, Garcia-Plata C, Garcia-Eroles L, Massons J, Comes E, Oliveres M, Targa C. Clinical study of 99 patients with pure sensory stroke. J Neurol $2005 ; 252: 156-62$

Accepted on 07-06-2005 